\title{
A EDUCAÇÃO DA INFÂNCIA ENTRE OS TRABALHADORES RURAIS SEMTERRA*
}

\author{
Luzia A. de Paula Silva **
}

\section{R E S U M O}

As diferentes abordagens teóricas tracejadas historicamente sobre a infância têm nos permitido reconhecê-la em processo de construção. Além disso, é possível perceber na dinâmica dessa constituição os vários aspectos das situações que estamos vivendo em relação à educação infantil, manifestações que podemos observar nos diferentes grupos e classes sociais, dentre outros. Assim, explicitaram-se determinadas preocupações, inquietações, tensões e conflitos nesse movimento e originou-se a necessidade de investigar a vida infantil, com o pretexto de realizar um estudo descritivo e explicativo sobre a educação da infância, em um grupo específico de trabalhadores rurais, pertencentes a um movimento social organizado que luta por melhores condições de vida e trabalho, contra a expropriação, exploração e alienação. Um dos objetivos centrais do grupo é a luta pela terra. Desenvolvemos esta pesquisa no Acampamento Oziel do Movimento dos Trabalhadores Rurais Sem Terra (MST), no município de Goiânia em 2001. Diante dessas premissas, é que nos motivamos a transformar a educação da infância em nosso objeto de estudo, analisando como os trabalhadores rurais sem terra concebem a educação das crianças de seu grupo, como representam e pensam o processo educativo.

PALAVRAS-CHAVE: Educação da infância - Grupo de trabalhadores rurais - Processo educativo.

\section{INTRODUÇÃO}

$\mathrm{C}$ om a preocupação em estabelecer um diálogo entre os vários conhecimentos relacionados à educação da infância é que nos envolvemos diretamente em estudos e discussões sobre os movi-

* O artigo é um recorte da dissertação A educação da infância entre os trabalhadores rurais sem terra, defendida no mestrado em Educação da UFG em agosto de 2002.

** Mestre em Educação pela FE/UFG, professora da rede municipal de ensino de Goiânia e membro da Secretaria Estadual do Colégio Brasileiro de Ciências do Esporte - GO. 
mentos sociais e as políticas públicas e educacionais voltadas para $o$ atendimento da infância.

De acordo com Eloísa Rocha (1999), abordar o tema significa discuti-lo a partir de concepções sobre a própria infância e a educação, compreendendo-as como categorias dinâmicas que implicam as transformações histórico-sociais.

Dentre os grupos sociais que reivindicam o acesso à educação da infância, podemos destacar os grupos organizados no campo, sobretudo aquele formado pelos trabalhadores rurais sem terra. Esse grupo luta para que sejam respeitadas as especificidades da infância de seus filhos, assim como mostra Miguel Arroyo (1994, p. 13): "a nossa preocupação com a política de educação da infância não surge pela caridade, pela afetividade, e sim pela consciência da obrigação pública que nós temos frente à infância". ${ }^{1}$

$\mathrm{Na}$ pesquisa e análise dos dados buscamos compreender sob quais perspectivas históricas, sociais, políticas, econômicas, ideológicas e culturais são encaradas as crianças e a educação entre os sem-terra. Escolhemos como campo de pesquisa o Acampamento Oziel, que se constituiu em Goiânia no ano de $2001^{1}$.

Ao desenvolver este estudo, buscamos compreender os sujeitos (crianças e adultos) do local, considerando o grupo do qual fazem parte. Realizamos a investigação diretamente no Acampamento Oziel através da análise de documentos e publicações do próprio MST, e de outros instrumentos, como entrevistas, depoimentos, fotografias e relatórios de observações.

\section{O SIGNIFICADO DA INFÂNCIA E DE SUA EDUCAÇÃO NO ACAMPAMENTO OZIEL}

No decorrer de nossa pesquisa, emergiram algumas categorias, baseadas na possibilidade de constituir um panorama sobre a educação da infância, as quais se encontram assim organizadas: o significado de infância e o tempo para estudar, brincar e trabalhar.

A compreensão do Movimento no que se refere à vida das crianças sem terra apresenta-se publicada em materiais do MST (1999, p. 13), com as seguintes afirmações: 
Sabemos que os sem-terrinha têm despertado a curiosidade dos que pensam, refletem a situação da infância no Brasil. Também têm sido campo de significado para muitos olhares e observações, desde que têm participado, junto com seus pais, de ocupações de terra, das mobilizações em busca de direitos, o que significa dizer que a luta pela Reforma Agrária é uma luta em família.

Para discorrermos sobre o significado de infância presente no Acampamento Oziel, consideramos os aspectos apresentados no decorrer das entrevistas. Tais aspectos envolvem a maneira como as crianças vivem, as diferentes atividades desenvolvidas por elas, as comparações sobre a infância vivida no acampamento e fora dele.

Uma das representações está baseada na infância vivida no acampamento, e abarca as condições materiais e o modo de viver das pessoas acampadas. Boa parte dos entrevistados expressou as necessidades mais comuns como um "momento de muitas dificuldades", em que, às vezes, "falta de tudo", alimentação, condições básicas de saúde, higiene, moradia e remédios.

Por outro lado, apesar dos enormes problemas vividos, é comum aparecer nas entrevistas um forte sentimento de alegria infantil, como uma forma positiva de viver no acampamento, balizado, a nosso ver, pela identificação com a vida, as pessoas e a luta. Isso parece indicar um bom entrosamento e envolvimento das crianças na vida cotidiana do lugar.

Soma-se a isso, uma preocupação em face da liberdade de ação das crianças, que precisam permanecer sob o olhar atento dos pais o maior tempo possível. Há indicativos em algumas famílias de que seus filhos ficam muito "soltos" no acampamento e portanto estas apresentam um cuidado quanto ao controle além de certa desconfiança com pessoas estranhas.

Ana Lúcia Faria (1999, p. 60) demonstra que, "com o pretexto de proteger a sua inocência, a criança é controlada, disciplinada e educada dentro dos novos valores sociais dominantes". Nesse sentido, podemos reconhecer que há por parte dos adultos uma preocupação com a educação da infância, mesmo que delimitando em determinados momentos a autonomia da criança ou refutando seus interesses infantis. 
Outra postura relevante em relação ao significado da infância vivida no Acampamento Oziel projeta-se na idéia de infância para o futuro, imbuída da necessidade de melhorar a vida das crianças. Há uma expectativa constituída a partir da conquista da terra, que tem em vista proporcionar outras vivências para os filhos, principalmente no que se refere à continuidade dos estudos.

José de Souza Martins (1993, p. 63) nos ajuda a compreender esse aspecto, segundo determinadas concepções que evidenciam "a infância como período da vida em que a criança se prepara para herdar". Durante as entrevistas, alguns acampados indicam uma educação dos menores com o fim de herdar as melhores produções cotidianas.

Associada a essa noção de infância para o futuro, apresentase a infância ideal, assim denominada por Sônia Margarida de Sousa (2001), na medida em que se idealizam a partir do cotidiano as perspectivas para o futuro das crianças.

Outra categoria que permeia a idéia sobre infância no Acampamento Oziel refere-se à infância sem futuro. Para alguns entrevistados, as crianças vivem uma "vidinha" que requer modificações no decorrer do processo de luta, o que implica a conquista da terra, vista como fator diferencial para a existência de uma outra infância.

Esse conceito de infância pautado pelo descrédito quanto a um futuro promissor está relacionado essencialmente à profissionalização. Desse prisma, a atual situação é concebida como fator limitador e projeta-se para o futuro a mesma relação vivenciada no acampamento, sem mencionar qualquer lance de esperança quanto a um futuro diferente.

Esses aspectos aqui apresentados dimensionam a educação da infância por meio de elementos como a contradição, oposição, conflitos, acordos, cumplicidades, observando-se um intenso movimento que varia de acordo com as relações entre os sujeitos nos grupos que freqüentam. Conceber a educação da infância, nessa dimensão, nos leva a considerá-la a partir das interações com vários elementos sociais, culturais, e políticos, e das relações entre os homens, as classes e o modo de produção capitalista. Com base nessas considerações compreendemos, como Ivone Garcia Barbosa (2002), a infância como um construto social. 


\section{O TEMPO PARA ESTUDAR}

A freqüência à Escola Itinerante Paulo Freire ${ }^{2}$ caracteriza-se como uma das atividades mais significativas na rotina diária das crianças pertencentes ao Acampamento Oziel, segundo as entrevistas e observações. Observam-se entretanto limitações relativas à estrutura e ao espaço escolar - cujos móveis são inadequados -, à falta de merenda e materiais didáticos, além da formação restrita dos educadores.

Os depoimentos e as entrevistas mostram que tanto os acampados quanto os educadores e as crianças têm um ideal de escola muito próximo da escola formal tradicional. Parece não haver perspectiva de constituir-se uma escola realmente opcional, com uma dinâmica própria que não essa do ensino fundamental. $\mathrm{O}$ modo ideal de educação precisa ser revisitado nas discussões daquele grupo de trabalhadores e pelo MST, e as crianças que falam e argumentam podem auxiliar na construção desse projeto.

O eixo da proposta de ensino do MST aponta para a organização de uma escola diferente; no entanto, em determinados momentos, ela se aproxima mais da concepção de escola tradicional. $\mathrm{Na}$ tentativa de oferecer uma nova proposta, Marlene Ribeiro (2001, p. 21) apresenta a necessidade de considerar a relação entre o trabalho cooperativo e a constituição de uma educação diferenciada. Essa intenção demandou do MST vários anos de luta, reflexões e discussões que ainda não se esgotaram, pois os desafios estão presentes no cotidiano, e a escola faz parte de uma construção social.

Roseli Caldart (1997, p. 40) defende "a possibilidade de uma escola que se vincule organicamente com a realidade do meio rural, ajudando nas transformações que ela exige". Além disso, notamos que há uma articulação orgânica entre os acampados, para manter organizada a equipe de educação do Acampamento Oziel, pois sob vários aspectos o Setor de Educação do MST, com toda a experiência acumulada, possui respaldo na área do ensino brasileiro.

\section{O TEMPO PARA BRINCAR}

Várias são as formas de brincar e jogar apontadas pelas crianças como atividades desenvolvidas por elas no Acampamento Oziel. 
Dentre essas, as mais comuns são: brincar de casinha, jogar bola, soltar pipa, pular corda, brincar com bambolê, ou seja, movimentar-se constantemente pelo acampamento.

A realização de brincadeiras no acampamento inicialmente gera a impressão de momentos meramente espontâneos, o que indica concepções que consideram a criança como ser isolado, individual, indiferente às relações e problemas sociais, refutando-a como sujeito ativo, dinâmico e que se constitui a partir das relações histórico-sociais. Nesse caso a infância é naturalizada, como se fosse movida por uma espécie de "essência infantil", um núcleo, uma tendência de ser criança e ter atitudes típicas e universais em cada idade.

Grande parte das crianças caracterizava o ato de brincar como uma das atividades de maior ocorrência entre elas nesse acampamento. Por um lado isso expressa a naturalização da brincadeira, desencadeando a noção de que as crianças brincam por brincar. No entanto, essa espontaneidade não pode por completo ser compreendida como um fator limitante, pois as crianças também criam suas regras no jogo, inventam e trocam papéis sociais, e abordam temas cotidianos. Todos esses elementos estão envolvidos no processo de brincar; enfim, essas relações estão impregnadas de significados e possuem como origem as relações sociais (Vygotsky, 1998).

Compreender a brincadeira apenas pela brincadeira, naturalizando as ações realizadas pelas crianças, denotaria incoerência teórica, de acordo com os pressupostos de vários estudiosos sobre esse tema. Vygotsky (1998), Henri Wallon (1975), Ivone Barbosa (2002) e Zilma Oliveira (1992), ao discutirem a brincadeira, enfatizam que nesses momentos a criança tem a possibilidade de experimentar e participar de várias situações envolvendo discussões, criação de regras, convenções e valores sociais.

Segundo Alexis Leontiev (1978, p. 288), as interações estabelecidas pelas crianças podem ser compreendidas por meio da seguinte estruturação:

$\mathrm{O}$ mundo dos homens que rodeiam a criança divide-se, por assim dizer, em dois círculos. O primeiro compreende os seus íntimos: a mãe, o pai ou aqueles que ocupam o seu lugar junto da criança; as suas relações 
com eles determinam as suas relações com o resto do mundo. $\mathrm{O}$ segundo círculo, mais largo, é constituído por todas as outras pessoas; as relações com elas são mediatizadas pelas relações estabelecidas no primeiro círculo, menor, quer a criança seja ou não educada na sua família.

No Acampamento Oziel, percebemos uma gama de condições favoráveis para as interações, no que tange à contribuição com a educação da infância, desde as relações próximas de amizade, família, grupos, escola, reuniões, jogos, até as situações de conflitos entre criança-criança e criança-adulto e as atividades realizadas pela Ciranda Infantil. ${ }^{3}$

\section{O TEMPO PARA TRABALHAR E DESENVOLVER OUTRAS ATIVIDADES}

Outras atividades cotidianas estão ligadas ao "trabalho", ou afazeres domésticos, realizados para auxiliar os pais, como lavar vasilhas ou roupas, carregar água, limpar a barraca, dentre outros.

Considerando os grupos familiares, não apenas esses ligados ao Acampamento Oziel, é comum identificarmos algumas atitudes que determinam às crianças a realização de serviços como: buscar um copo com água, pegar algum objeto distante do adulto e levar recados. Essa é uma das formas de tratar as crianças, aqui apresentada por Míriam Leite (1997, p. 18), ao analisar a infância no século XIX através dos livros de viagens e memórias.

No século XIX, criança, por definição, era uma derivação das que eram criadas pelos que lhes deram origem. Eram o que se chamava de "crias" da casa, de responsabilidade (nem sempre assumida inteira ou parcialmente) da família consangüínea ou da vizinhança.

Essas afirmações já foram analisadas por outros autores, como Marisa Lajolo (1997), Kátia Mattoso (1996) e Ivan Russef (1997), e demonstram que as tarefas destinadas às crianças deveriam ser cumpridas, sob a penalidade de serem castigadas. Não queremos afirmar com isso que as atividades desenvolvidas pelas crianças no Acampamento Oziel estejam definidas nessas condições. 
Os afazeres realizados por elas passam, a princípio, pela organização e necessidade da própria família, já que muitas tentam assegurar a atribuição de tarefas menos difíceis para as crianças. Nas entrevistas, muitas delas dizem que na escola também há essa delegação de tarefas, incluindo-se as crianças na organização, limpeza e arrumação das salas, e na reposição de água nos filtros.

No acampamento, esses trabalhos fazem parte de um conjunto de ações concebidas como necessárias para a formação infantil. Baseiam-se nos princípios de organização do MST, com a intenção de promover a participação das crianças em atividades coletivas e contribuir com a organização do acampamento.

Martins (1993), ao analisar o componente "trabalho" em pesquisas com crianças, justifica que em parte elas migram com os pais, objetivando chegar à terra para trabalhar. Com isso, acrescenta-se uma outra perspectiva a essa situação, pois a realidade das famílias camponesas, cujo sustento está vinculado ao trabalho agrícola ou ao desenvolvimento de outras atividades, é a da incorporação das crianças a esse serviço.

Nessa discussão sobre trabalho, o que nos interessa são as relações sociais estabelecidas entre os sujeitos, pois esse é o ponto de partida para o debate das atividades e para o conjunto das entrevistas, realizadas coletivamente ou individualmente.

Leontiev (1978) apresenta essa discussão no âmbito da "actividade dominante", explicitando que essa não está relacionada somente aos dados quantitativos ou ao tempo em que as crianças permanecem desenvolvendo determinado trabalho.

A actividade dominante é, portanto, aquela cujo desenvolvimento condiciona as principais mudanças nos processos psíquicos da criança e as particularidades psicológicas da sua personalidade num dado estádio do seu desenvolvimento. (Leontiev, 1978, p. 293)

No acampamento, as crianças participavam também de outras atividades, como vigiar carro, vender produtos manufaturados, entre outras, a fim de obterem parte do próprio sustento. 


\section{CONSIDERAÇÕES FINAIS}

Ao longo de nosso trabalho procuramos traçar algumas considerações, ensejando um processo contínuo e dinâmico com os dados obtidos em nossa pesquisa. Foi fundamental para isso considerar a infância na condição de construto social, levando-se em conta as relações e práticas sociais em que ela se constitui. Portanto, "sendo a infância uma produção histórica, não poderemos, hoje, na sociedade capitalista, pensá-la em abstrato, referindo-nos à criança independentemente de sua classe social" (Faria, 1999, p. 61).

No Acampamento Oziel, esses elementos pautaram-se na definição de criança e de infância, e nas representações sobre a vida infantil. Tais representações foram indicadas através das atividades mais desenvolvidas pelas crianças e da perspectiva dos acampados em relação ao MST, com alusão constante à sua situação real. Daí resultaram algumas impressões sobre a educação da infância, estruturadas em categorias relativas ao estudo sistemático e à realização de atividades que envolvem a brincadeira e o trabalho.

Outro ponto que permeia a versão sobre a educação infantil, sendo comum entre adultos e crianças do acampamento, está relacionado à necessidade de superar as carências vigentes no local, que abrangem a falta de alimentos, lanche na escola e outras. É drástico como esses problemas são apresentados: para alguns a miséria é tão acentuada que sentem dificuldades em acreditar que a situação pode ser diferente.

Podemos então afirmar que, embora alguns acampados vejam as crianças como "amontoadas", o fato de poderem conviver com pares e adultos torna-se favorável à constituição de certos conhecimentos ligados à cultura rural e a outras culturas, na medida em que se tomam os espaços de interações para a apropriação de hábitos, conceitos, valores e idéias.

$\mathrm{Na}$ condição de acampados, os adultos estão interligados pela luta em comum e, portanto, necessitam se organizar, constituir-se em equipes, núcleos coletivos e coordenações para garantir desenvolvimento cotidiano dentro e fora do acampamento. Esses aspectos também são discutidos com as crianças, o que lhes dá um estatuto de seres ativos, contribuindo para se ver a infância não apenas como fase passiva. 
Portanto a educação da infância é marcada por elementos variados e contraditórios, havendo necessidade de discutir-se melhor as formas de aproveitamento dessas contradições nos projetos do próprio MST.

Certamente toda essa movimentação influencia na concepção que as próprias crianças têm de educação. Para elas, apesar de ser fundamental na infãncia a atividade de brincar, não a desligam do estudar e do trabalhar, uma demonstração de que para a classe trabalhadora não se pode naturalizar uma única atividade como principal, quando se vivem e se assumem as experiências coletivas, como no Acampamento Oziel.

\title{
Infant Education Among Rural Landless Workers
}

\begin{abstract}
A B S T R A C T
The different theoretical approaches historically traced involving infancy have allowed us to recognize it in construction processes. Moreover, it is possible to notice, in the dynamics of this constitution, the many aspects that create the situations we are now living in relation to infant education, manifestations that we can observe in different social groups and classes, among others. With this perception, certain preocupations, queries, tensions and conflicts arised in this movement, originating the need to investigate infant life, with the aim of carrying out a descriptive and explanatory study about the education of infants, related to a specific group of rural workers who are organized in a social moviment that fights for better conditions of life and work, against exploitation, alienation and the loss of land, with the fight for land being one of their main aims. We developed this research at a camp called Acampamento Oziel that belongs to MST, in the city of Goiania in 2001. Based on these premises, we decided to take the education of infants as our object of study, analysing how rural workers who have no land carry out the education of children within their group, how they represent and how they think about the educational process.
\end{abstract}

KEY WORDS: Infant Education - Rural workers group - Educational process.

\section{NOT A S}

1. A formação do Acampamento Oziel ocorreu através da articulação de vários acampamentos: Dom Hélder Câmara (Itaberaí), Antônio Conselheiro (Guapó), Raio de Sol (Chapadão do Céu), acampamento de Niquelândia (Niquelândia), Capimpuba (Goiânia) e o pré-assentamento Canudos, que abrange os municípios de Palmeiras de Goiás, Guapó e Campestre. O seu surgimento fez parte das atividades previstas no calendário 
nacional de lutas do MST, que incluía ocupações, formação de acampamentos, atividades nos assentamentos e atos políticos.

2. A Escola Itinerante Paulo Freire, foi inaugurada no dia 12 de maio de 2001, em solenidade no próprio acampamento. Caracteriza-se por experiências implantadas em outras regiões do Brasil, seguindo um modelo de escola que acompanha o acampamento nas mudanças de locais ocorridas em função das necessidades, estratégias e negociações do MST.

3. A Ciranda Infantil é um espaço organizado nos acampamentos e assentamentos, de acordo com as condições e necessidades de cada lugar, e na realização de eventos como: congressos, encontros estaduais, nacionais, cursos e outras ações do MST. Constitui-se em um espaço destinado ao desenvolvimento de atividades variadas: ler, escrever, pintar, desenhar, contar e inventar histórias, passear. Essas informações foram recolhidas no site do MST: www.mst.org.br.

\section{R E F E R E N C I A S}

ARROYO, Miguel. A construção social da infância. In: SEMINÁRIO: INFÂNCIA NA CIRANDA DA EDUCAÇÃO - UMA PROPOSTA POLÍTICO-PEDAGÓGICA PARA ZERO A SEIS. ContagemMG: CAPE/SMED, 1994. p. 11-17.

BARBOSA, Ivone Garcia. Educação da infância: historicidade e desafios atuais. Goiânia: SBPC, 2002. Mimeografado.

CALDART, Roseli Salete. Educação em movimento: formação de educadores e educadoras no MST. Petrópolis, RJ: Vozes, 1997.

FARIA, Ana Lúcia G. Infância, educação e classe operária. In: Pré-escolar e cultura. Campinas, SP: Cortez, 1999. p. 55-100.

LAJOLO, Marisa. Infância de papel e tinta. In: FREITAS, M. C. (Org.). História social da infância no Brasil. São Paulo: Cortez, 1997. p. 225-246. 
LEITE, Míriam L. Moreira. A infância no século XIX segundo memórias e livros de viagem. In: FREITAS, M. C. (Org.). História social da infância no Brasil. São Paulo: Cortez, 1997. p. 17-50.

LEONTIEV, Alexis. O desenvolvimento do psiquismo. Lisboa: Livros Horizonte, 1978.

MARTINS, José de Souza. O massacre dos inocentes: a criança sem infância no Brasil. São Paulo: Hucitec, 1993.

MATTOSO, Kátia Q. O filho da escrava. In: DEL PRIORE, M. (Org.). História da criança no Brasil. São Paulo: Contexto, 1996. p. 76-97.

MST. Crianças em movimento: as mobilizações infantis no MST. Porto Alegre, 1999. (Coleção Fazendo Escola, 2).

MST. Educação infantil: construindo uma nova criança. Disponível em: http://www.mst.org.br. Acesso em 2001.

OLIVEIRA, Zilma Moraes. Creches: criança, faz-de-conta \& cia. Rio de Janeiro: Vozes, 1992.

RIBEIRO, Marlene. Trabalho cooperativo no MST e ensino fundamental rural: desafios à educação básica. Revista Brasileira de Educação, Campinas, n. 17, maio/jun./jul./ago. 2001.

ROCHA, Eloísa A. C. A infância e a pedagogia. In: A pesquisa em educação infantil no Brasil: trajetória recente e perspectiva de consolidação de uma pedagogia da educação infantil. Florianópolis: Centro de Ciências da Educação. Núcleo de Publicações, 1999. p. 37-52.

RUSSEFF, Ivan. A infância no Brasil pelos olhos de Monteiro Lobato. In: _. História social da infância no Brasil. São Paulo: Cortez, 1997. p. 247-268.

SNYDERS, Georges. Escola, classe e luta de classe. 2.ed. Lisboa: Moraes, 1981.

SOUSA, Sônia Margarida de. (Coord.). O significado da infância, educação e violência física contra os filhos. Goiânia: Editora da UCG, 2001. 
VYGOTSKY, Lev Semyonovich. A formação social da mente. São Paulo: Martins Fontes, 1998.

WALLON, Henri. Psicologia e educação da infância. Lisboa: Estampa, 1975.

Recebido: Setembro de 2002 Aprovado: Novembro de 2002

Endereço para correspondência Luzia A. de Paula Silva Rua R-45 Qd. 44 Lt. 32 Conjunto Itatiaia I Goiânia - Goiás CEP 74690-700 